\title{
The Value of Semen Freezing and Artificial Insemination Techniques for Preservation of Onagadori, the Japanese Long-Tailed Fowl
}

\author{
Francine A. Bradley and Frank X. Ogasawara \\ Department of Avian Sciences, University of \\ California, Davis, California 95616
}

Onagadori, the Japanese Long-Tailed Fowl, have been raised in Japan since the 18th century. The breed was developed by farmers in the Tosa district who selected long-tailed stock from the shokoku breed (OANA, 1954). The Onagadori trademark, the long tail, is a unique physiological phenomenon. The males of the breed are the only chickens that never molt their tail feathers.

In 1923 the Onagadori were declared Natural Commemorated Objects (OgASAwARA, 1970). As such they are an official segment of Japan's heritage. The breed was almost annihilated during World War II, but the Japanese breeders were able to rebuild the population.

Unfortunately, the breed is still far from numerous and it seems imperative to investigate means whereby the breed can increase in size and be assured of a secure future. The intent of this research was to utilize various semen freezing and artificial insemination techniques with Onagadori.

\section{Experimental}

Semen was collected from 10 Onagadori males approximately 1 year of age. The birds were the sixth generation of stock brought from Japan in 1970 by Dr. F.X. Ogasawara and bred at the Department of Avian Sciences, University of California, Davis. The males were housed in individual wire cages in a light-and temperaturecontrolled facility: $14 \mathrm{~L}: 10 \mathrm{D}$ and $23.3^{\circ} \mathrm{C}$. Semen collection was performed every Monday, Wednesday, and Friday for 10 weeks.

Volume, motility, and concentration measurements were made on each day's pooled semen sample. Motility was scored on a 0 to 5 scale, a score of 5 being optimum. The pre-freeze treatment was to dilute the fresh whole semen 1:3 with Beltsville Poultry Semen Extender; cool for $1.0 \mathrm{hr}$ at $5^{\circ} \mathrm{C}$.; add $4.0 \%$ dimethylsulfoxide (DMSO); and equilibrate at $5^{\circ} \mathrm{C}$. for an additional $1.0 \mathrm{hr}$. The pre-freeze treated sample was frozen in the following manner: frozen at $1^{\circ} \mathrm{C} . / \mathrm{min}$ from +5 to $-20^{\circ} \mathrm{C}$. in a control rate freezer; exposed to a liquid nitrogen vapor temperature of approximately $-110^{\circ} \mathrm{C}$. for $15 \mathrm{~min}$. ; and then plunged and stored in liquid nitrogen $\left(-196^{\circ} \mathrm{C}\right)$.

For the fertility trials 28 virgin Onagadori pullets were used. The birds were divided into 2 groups of 14 each-Control and Experimental. Every Monday each group 
of Control and Experimental pullets was inseminated intravaginally (IV) with 125 million fresh, whole or frozen-thawed spermatozoa, respectively. The frozen semen was thawed for insemination in a $2-3{ }^{\circ} \mathrm{C}$. ice bath. The experimental inseminations were repeated on Thursdays. The inseminations were carried out over a 3 -week period for a total of 6 Experimental and 3 Control inseminations.

Eggs were collected daily and set weekly. Fertility and embryonic mortality were determined by candling and egg break-out on days 7 and 17 .

Statistical analyses were performed according to LitTle and Hills (1978).

\section{Results and Discussion}

For Monday, Wednesday, and Friday, respectively, the mean semen volume, motility, and concentration scores were: $1.28,1.09,1.35 \mathrm{ml} ; 4.5,4.5,4.6 ; 4.25,4.5$, and $4.5 \times 10^{9}$ spermatozoa $/ \mathrm{m} l$. These values indicated that the fresh whole semen was of good quality and most importantly sufficient volume for freezing studies could be obtained from 10 males. The problem of small ejaculates can be a severe experimental handicap when working with exotic breeds that have not been selected for reproductive performance.

Using the pre-freeze and freezing procedures described it was possible to obtain frozen-thawed semen with motility scores as high as 3.5. The resultant fertility and hatchability data from the control and experimental inseminations are found in Table 1. There was a highly significant difference in fertility, $75.9 \%$ compared to $11.8 \%$, for the control and experimental groups, respectively. Therefore, it appears that the treatment had a significant and deleterious effect on the fertilizing capacity of the frozen-thawed spermatozoa. Despite the depression in fertility, the experimental eggs hatched well. Over the 3 week period, 12 experimental chicks were hatched. They were the first Onagadori chicks ever produced from eggs fertilized with frozen-thawed semen (Fig. 1).

The experimental fertility values were lower than expected. Higher fertility values have been reported; however, in most cases the cryoprotectants and insemination

Table 1. Fertility and hatchability data for Control and Experimental Onagadori pullets inseminated with fresh, whole semen and frozen-thawed semen, respectively.*

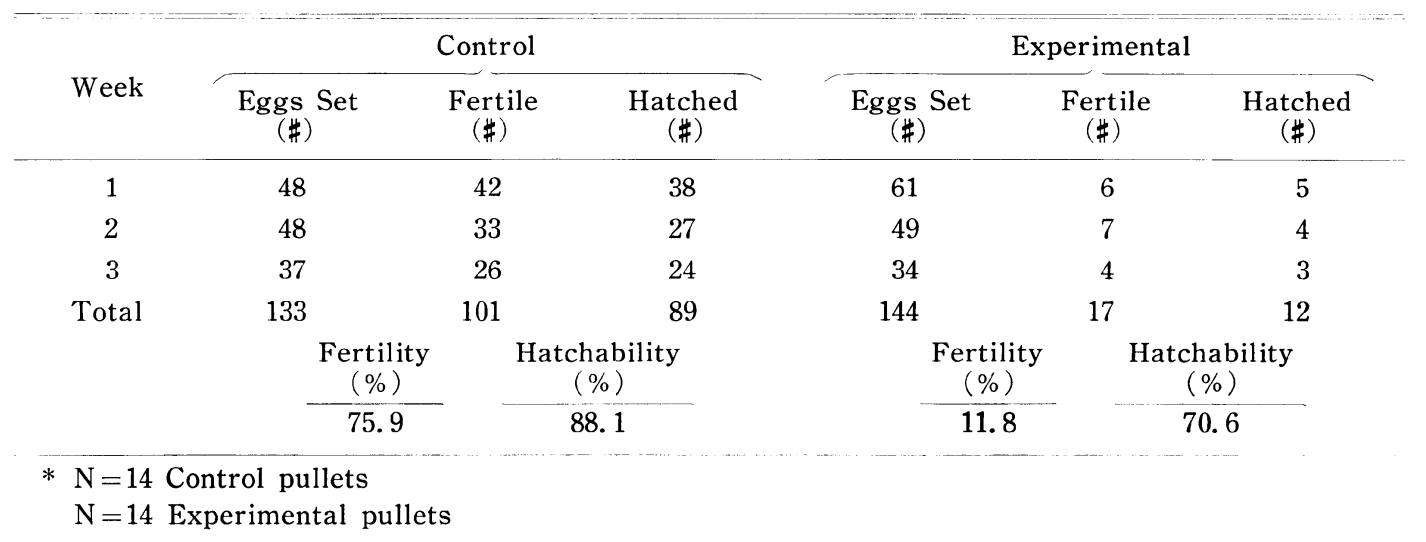




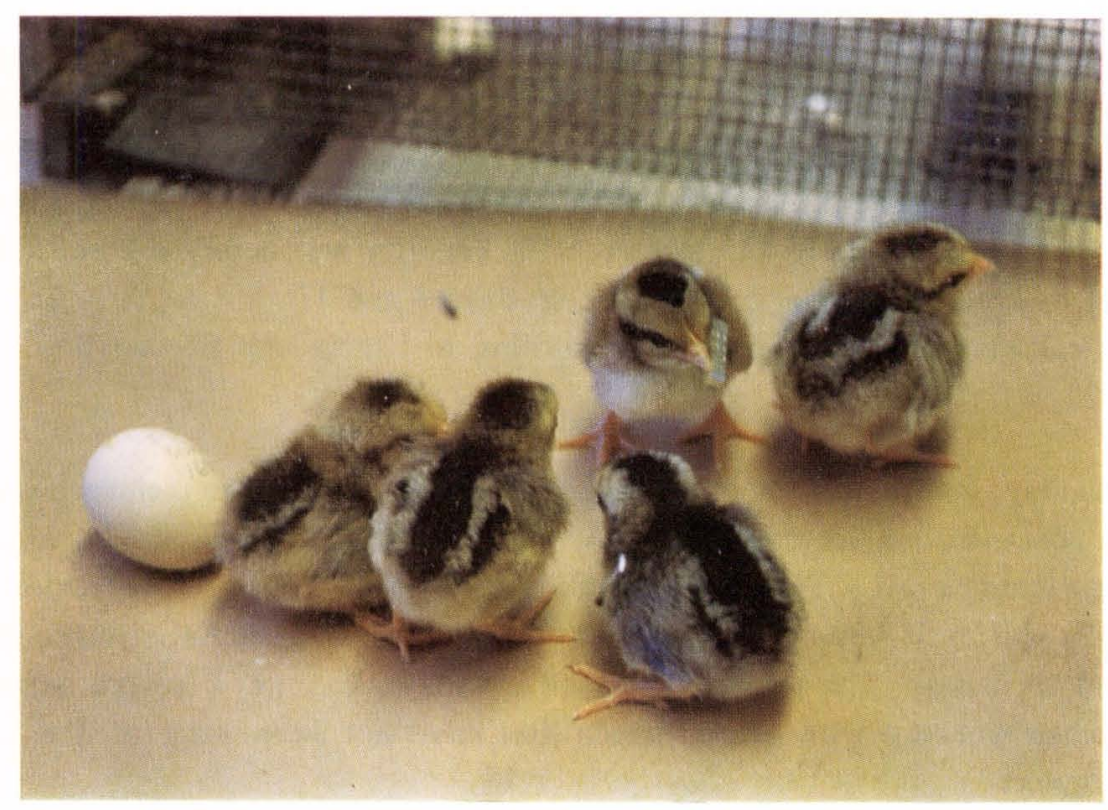

Fig. 1. First Onagadori chicks produced from eggs fertilized with frozen-thawed semen; shown at day of hatch.

techniques differed from those used in this experiment.

Watanabe, Miura, and Moda (1970) obtained 60\% first-week fertility with frozenthawed semen using $7.0 \%$ glycerol as a cryoprotectant. However, the reported hatchability was quite low $-56.6 \%$. Allen (1958) was able to obtain $25.0 \%$ fertility with glycerolised semen, but the treatment required intrauterine (IU) inseminations. The cryogenic treatment most similar to the one reported in this paper was described by Bakst and Sexton (1978). Also using DMSO and IV inseminations they obtained 55\% fertility with frozen-thawed semen.

Another point to be considered is the fact that in most semen freezing experiments, the stock used is from a line selected for reproductive performance. ScotT et al. (1978) reported an improvement in fertilizing capacity of frozen-thawed semen after four generations of selection. Possibly, with selection a strain of Onagadori could be developed that would be more responsive to inseminations with frozen-thawed semen.

Finally, this experimentation demonstrated the feasibility of freezing semen from Onagadori. Having the male gametes in a frozen state would allow for exchange of stock between breeders separated by great distances. Such a system would avoid also the complication of quarantine regulations. Artificial insemination, of course, would be required to use the frozen-thawed semen. It is a technique that could prove very useful to breeders of Onagadori. Currently, cocks that do not readily adapt to the tomebakos, and therefore have short tails, are used as sires. However, artificial collection of semen would allow breeders to obtain semen from the show quality cocks whose long tails would be an impediment to natural mating. One of the most attrac- 
tive aspects of the described procedure is that the frozen-thawed semen can be inseminated IV. This would be especially helpful to fanciers who would be unable to perform surgical insemination (IU).

Hopefully the information reported here will in some way aid in the growth of one of the world's spectacular breeds of chicken-Onagadori.

\title{
Summary
}

Experiments were conducted to determine the feasibility of applying semen freezing and artificial insemination techniques to Onagadori breeding programs. It was possible to freeze the semen, store it in liquid nitrogen, inseminate Onagadori pullets IV with 125 million frozen-thawed spermatozoa each, and obtain fertile eggs and chicks. These results suggest that semen freezing and AI may be valuable tools for maintaining this historically and physiologically significant breed.

\section{Acknow ledgement}

The authors wish to thank Mr. Byron Muller, Principal Animal Technician, Department of Avian Sciences, University of California, Davis for his expert care of the Onagadori population.

\section{Literature}

Allen, T.E.: Proc. Austr. Soc. Anim. Prod., 2, 118, 1958.

Bakst, M.R. and T.J. Sexton: Poultry Sci., 57, 1116, 1978.

Little, T.M. and F.J. Hills: Agricultural experimentation: design and analysis. John Wiley and Sons, Inc., New York, 1978.

OAna, H.: World's Poult. Congr. Proc. X: 9, 1954.

Ogasawara, F.X.: Ntl. Geogr.: 138, 845, 1970.

Scott, T., G. Ansah, R. B. Buckland and B. W. Kennedy: Poultry Sci., 57, 1161, 1978.

Watanabe, M., M. Miura and Y. Moda: Jap. Poult. Sci., 1, 23, 1970.

\section{尾長鶏, 日本長尾鶏の保存における精液凍結 および人工授精技術の価值}

\author{
Francine A. Bradley and F. X. Ogasawara \\ カリフォルニャ大学家禽科学科, Davis, California 95616
}

